RESEÑA

\title{
JORNADA DE GANADORES ${ }^{1}$
}

Catalina Salas-Durán ${ }^{2}$

La Escuela de Zootecnia de la Universidad de Costa Rica, con apoyo de la Vicerrectoría de Investigación, realizó una jornada de reconocimiento a cinco jóvenes profesionales que durante su paso por las aulas participaron del concurso Científico Joven de Alltech y obtuvieron puestos de privilegio. La intención era, además de reconocer a estos jóvenes investigadores por sus trabajos ganadores, incentivar a las nuevas generaciones de estudiantes del área de producción animal a realizar investigación de calidad y participar en este u otros concursos.

Durante la jornada se contó con la presencia de autoridades universitarias a través de representantes de vicerrectores, directores de escuela, directores de centros de investigación, directores de estaciones experimentales, y directores de programas e institutos. Adicionalmente, estuvieron presentes representantes de la empresa Alltech, representantes del Servicio Nacional de Salud Animal (SENASA), directores ejecutivos de cámaras relacionadas con el gremio, miembros de prensa y estudiantes de la carrera de Zootecnia y afines.

El Premio Alltech Young Scientist (premio al Científico Joven Alltech) es un concurso que tiene 10 años de existencia y que invita a jóvenes investigadores a participar con sus ponencias a nivel de grado y posgrado con temas relacionados con el quehacer agropecuario. El concurso busca promover a los estudiantes a presentar soluciones agropecuarias innovadoras que busquen un desarrollo sostenible.

El concurso está dividido en fases. Inicialmente se realiza una fase regional, en este caso toda América Latina. Todas las ponencias son evaluadas por un equipo de jueces expertos en los diferentes temas y en cada región se seleccionan las mejores propuestas. Posteriormente, se continúa con la fase global, en donde los ganadores regionales

\footnotetext{
${ }^{1}$ Evento realizado por la Escuela de Zootecnia, Universidad de Costa Rica. Miércoles 6 de mayo, 2015 ${ }^{2}$ Universidad de Costa Rica. Revista Nutrición Animal Tropical, Editora. Autora para correspondencia: revistanat.ez@ucr.ac.cr

Recibido: 9 de mayo 2015 Aceptado: 10 de mayo 2015
} 
compiten entre sí y realizan una presentación oral de la ponencia frente a un grupo de jueces en Lexington, Kentucky cada mes de mayo.

Entre el año 2011 y 2015, estudiantes de la Escuela de Zootecnia se han animado a participar del concurso. En todos los años, sin excepción, alguno de ellos ha resultado finalista en la fase regional, lo cual motivó a la Escuela de Zootecnia a realizar este evento. Estos logros reflejan que la Universidad de Costa Rica es una institución líder en la producción de investigación innovadora, actualizada y relevante.

La presentación de las ponencias se realizó en el auditorio de la Unidad del Conocimiento de Agronomía en la Facultad de Ciencias Agroalimentarias. Se inició la jornada con la presentación de Jeffry Sánchez Salas, quien ofreció su charla vía videoconferencia, pues se encuentra realizando estudios de posgrado en la Universidad de Wageningen, Holanda. El título de su ponencia fue: "Caracterización del estado inmunológico de terneros de lechería en la Región Huetar Norte de Costa Rica", el cual le confirió el cuarto lugar en el Altech Young Scientist Award Latinoamérica 2012. El objetivo de su estudio fue realizar una caracterización del estado inmunológico de terneras y terneros de lechería en la región Huetar Norte de Costa Rica. Para tales fines se evaluó la adquisición de inmunidad pasiva a través de la medición de la concentración de proteína sérica total en sangre, y el efecto por sexo del animal, raza, cantidad de partos de la madre y vía de alimentación (amamantamiento o chupón). Entre los resultados se puede destacar que de todos los animales evaluados un 31,8\% presentaron niveles inadecuados de inmunidad. Se encontró un efecto por sexo y raza del animal en la concentración de proteína sérica total y una menor proporción de animales con inmunidad adecuada cuando las crías permanecieron con la madre. Entre las conclusiones presentadas se sugiere la necesidad de establecer prácticas de manejo del calostro que permitan minimizar el riesgo de terneros con una transferencia de inmunidad pasiva inadecuada en hatos lecheros de la región Huetar Norte de Costa Rica.

El mismo charlista continuó con la segunda ponencia, pues en el año 2015 resultó ganador del primer lugar Alltech Young Scientist Award en Francia, a nivel de posgrado. Su propuesta se denominó: "Suplementación con selenio orgánico y su efecto sobre la producción, composición y contenido de selenio en leche de vacas lecheras en pastoreo". Con este proyecto de pretendió evaluar el efecto de la suplementación con levadura selenizada, derivada de una cepa específica de Saccharomyces cerevisiae (CNCM I- 
3060), sobre el comportamiento productivo, reproductivo y las concentraciones de selenio en la leche de vacas lecheras en pastoreo. Durante su estudio utilizó vacas multíparas de la raza Holstein, las cuales fueron asignadas al azar a un tratamiento control, que consistió de una dieta basal que suministró $0,7 \mathrm{mg}$ de selenio/kg $\mathrm{MS}$, o un tratamiento experimental que consistió de la misma dieta basal suplementada con 3,0 mg de selenio, del día 5 al 56 de lactancia. Se evaluaron las siguientes variables: producción y composición de la leche, el contenido de células somáticas y el contenido de selenio en la leche. La suplementación con selenio orgánico aumentó la eficiencia aparente de transferencia de selenio a la leche y el contenido de selenio de la misma, por lo que la leche derivada de vacas suplementadas con selenolevadura podría ser una vía útil para contribuir a la ingesta diaria de selenio en humanos. Esto permitiría alcanzar las recomendaciones dietéticas diarias de este mineral y que contribuya como alimento funcional a solventar problemas relacionados con la deficiencia de este nutriente.

La jornada continuó con la presentación de Walter Rivera Pérez, quien con el tema: "Nutrición, Salud y Bienestar Animal en Pollo de Engorde: El Impacto de la Tendencia en las Preferencias del Consumidor" fue reconocido con el segundo lugar Alltech Young Scientist Award Latinoamérica 2011. La propuesta se centraba en utilizar todas las herramientas disponibles para tener un mejor desempeño de las aves. En la ponencia se discutieron temas de bienestar animal, inocuidad de alimentos, trazabilidad y conservación del medio ambiente. La propuesta logra destacar como existe una relación directa entre la nutrición y la salud de los animales, y cómo eso afecta su bienestar. Se propone entonces la utilización de estrategias nutricionales que mejoran la salud del ave, tal como el uso de antioxidantes, mananos oligosacáridos, aminoácidos, complejos de minerales orgánicos, $\beta$ 1-3 glucanos, enzimas, ácidos orgánicos, probióticos, entre otros. Estas estrategias ayudan a lograr un mejor sistema inmune del ave, lo que le ayuda a enfrentar con mayor éxito los desafíos de campo. Lo anterior es también percibido por los consumidores, quienes buscan un mejor trato para los animales y con esto una alta calidad de los productos que provienen de los mismos.

El siguiente charlista fue Nelson Peña Navarro, quien resultó ganador de primer lugar Altech Young Scientist Award Latinoamérica 2013 con el tema: "Efecto estimulador de tres productos naturales sobre el sistema inmunológico del camarón Litopenaeus vannamei, para prevenir y controlar Vibrio spp". Con este tema, Nelson participó de la 
fase global de ese año en Lexington, Kentucky durante el Simposio Internacional de Alltech. El objetivo de su proyecto fue determinar la respuesta inmunológica del camarón Litopenaeus vannamei utilizando tres alternativas frente a un desafío con Vibrio parahaemolyticus (Manano-Oligosacátidos, Ajo y un compuesto de extractos de plantas). Durante el ensayo se evaluó la ganancia de peso y la conversión alimenticia y luego de la infección con $V$. parahaemolyticus se realizaron hemogramas, coagulación, bacteriología de hemolinfa, mortalidad acumulada y análisis histológicos. Los parámetros inmunológicos no mostraron diferencias entre los tratamientos, sin embargo, los parámetros zootécnicos sí. El tratamiento con ajo presentó mejores resultados, al tener un mayor peso final de biomasa, un incremento en la ganancia de peso y una mejor conversión alimenticia. El análisis histológico demostró ser el mejor parámetro para medir el efecto inmunoestimulante, donde los mananologosacáridos y el ajo mostraron los mejores resultados para esta variable.

Seguidamente Mónica Madrigal Valverde presentó su ponencia "Ganadería y mejoramiento genético en Costa Rica: productividad en cruzamientos Bos indicus, Región Pacífico Norte" con la cual ganó el tercer lugar Alltech Young Scientist Award Latinoamérica 2014. Su trabajo consistió en un análisis del comportamiento de características productivas en bovinos Bos indicus (peso al nacimiento, pesos y ganancias diarias de peso al destete, al año de edad y a los 18 meses de edad. Ella utilizó una base de datos de registros productivos en finca (2002-2012), ubicada en la Región Pacífico Norte de Costa Rica, provincia de Guanacaste. Los grupos raciales que se incluyeron en el estudio fueron: 1/2Brahman 1/2Gucerá, 1/2Brahman 1/2Nelore, 1/4Brahman 3/4Nelore, 1/4Nelore 3/4Brahman, Brahman puro, Nelore puro y Gucerá puro. El análisis de promedios determinó que el grupo racial con mayores promedios para peso al nacimiento fueron el grupo $1 / 2$ Brahman $1 / 2$ Gucerá. El mejor promedio para peso al destete y ganancia diaria de peso fue para el grupo Nelore, mientras que para peso al año y ganancia diaria al año el mejor grupo fue $1 / 4$ Nelore $3 / 4$ Brahman. A los 18 meses de edad, el grupo que presenta los mejores parámetros fue $1 \frac{1}{2}$ Brahman $1 / 2$ Nelore. El análisis según el grupo racial de la madre indica que los mayores promedios fueron para hembras Brahman en peso al nacimiento. Así mismo, las madres Nelore presentan los mejores promedios para peso al destete, peso al año y peso a 18 meses, además de las respectivas ganancias de peso. Según grupo racial del padre, los Gucerá producen crías más pesadas para peso al nacimiento, mientras que los padres Brahman tienen crías con mejores pesos para peso al destete y a 
18 meses, y sus respectivas ganancias. Los sementales Nelore producen crías con mejores pesos y ganancias al año de edad.

La jornada finalizó con la participación de Omar Vargas Villalobos, quien ganó el primer lugar Altech Young Scientist Award Latinoamérica 2015 con el tema "Efecto de dos niveles de proteína cruda y suplementación con hidroxianálogo de metionina en el desempeño productivo de vacas lecheras". Omar estaría participando con este tema en el Simposio Internacional de Altech 2015. Su proyecto consistió en evaluar dos niveles de proteína cruda en la dieta (estándar 15,8\% y alto 16,6\%) con o sin suplementación de hidroxianálogo de metionina HMTBA (25 g de MFPTM, NOVUS International Inc., USA) en vacas multíparas de la raza Holstein. Se evaluó la producción láctea, composición láctea y nitrógeno ureico en leche (NUL). No se observaron diferencias significativas en producción leche, leche corregida al $4 \%$ de grasa, composición y producción de grasa y proteína láctea en los tratamientos estudiados. Sin embargo, se observó una tendencia positiva en composición de grasa y proteína láctea al adicionar el aditivo al nivel estándar de proteína cruda. Alimentar las vacas con alto nivel de proteína cruda incrementó significativamente el valor de nitrógeno uréico en leche pero no se encontraron diferencias al adicionar el suplemento.

La jornada ofreció un conjunto amplio y diverso de temas de investigación desarrollados por jóvenes estudiantes, lo cual indica que todavía hay mucha investigación que realizar en el área agropecuaria que es relevante para el sector productivo. La jornada también permitió evidenciar una excelente calidad en las investigaciones, lo cual refleja una gran capacidad de análisis en los estudiantes, bajo la tutela de profesores altamente calificados. Actividades como ésta incentivan, tanto a los estudiantes como a los docentes, a continuar con la ardua labor de generar conocimiento innovador y de impacto. 